OPEN ACCESS

Edited by:

Nadine Ravel,

INSERM U1028 Centre de Recherche en Neurosciences de

Lyon, France

Reviewed by:

Christiane Linster,

Cornell University, United States

Ricardo C. Araneda,

University of Maryland, College Park,

United States

*Correspondence:

Max L. Fletcher

mfletch4@uthsc.edu

Received: 09 April 2019 Accepted: 08 July 2019

Published: 19 July 2019

Citation:

Ross JM, Bendahmane M and Fletcher ML (2019) Olfactory Bulb Muscarinic Acetylcholine Type

1 Receptors Are Required for Acquisition of Olfactory

Fear Learning.

Front. Behav. Neurosci. 13:164. doi: 10.3389/fnbeh.2019.00164

\section{Olfactory Bulb Muscarinic Acetylcholine Type 1 Receptors Are Required for Acquisition of Olfactory Fear Learning}

\author{
Jordan M. Ross ${ }^{1}$, Mounir Bendahmane ${ }^{2}$ and Max L. Fletcher ${ }^{1 *}$ \\ ${ }^{1}$ Department of Anatomy and Neurobiology, University of Tennessee Health Science Center (UTHSC), Memphis, TN, \\ United States, ${ }^{2}$ Department of Pharmacology, University of Michigan, Ann Arbor, MI, United States
}

The olfactory bulb $(\mathrm{OB})$ receives significant cholinergic innervation and widely expresses cholinergic receptors. While acetylcholine (ACh) is essential for olfactory learning, the exact mechanisms by which ACh modulates olfactory learning and whether it is specifically required in the $\mathrm{OB}$ remains unknown. Using behavioral pharmacology and optogenetics, we investigated the role of $\mathrm{OB}$ ACh in a simple olfactory fear learning paradigm. We find that antagonizing muscarinic ACh receptors (mAChRs) in the $\mathrm{OB}$ during fear conditioning but not testing significantly reduces freezing to the conditioned odor, without altering olfactory abilities. Additionally, we demonstrate that $\mathrm{m} 1 \mathrm{mAChRs}$, rather than $\mathrm{m} 2$, are required for acquisition of olfactory fear. Finally, using mice expressing channelrhodopsin in cholinergic neurons, we show that stimulating ACh release specifically in the $\mathrm{OB}$ during odor-shock pairing can strengthen olfactory fear learning. Together these results define a role for ACh in olfactory associative learning and OB glomerular plasticity.

Keywords: olfaction, fear learning, acetylcholine, muscarinic, olfactory bulb, pharmacology, behavior

\section{INTRODUCTION}

The olfactory bulb $(\mathrm{OB})$ receives significant input from neuromodulatory centers that release norepinephrine, serotonin, and acetylcholine (ACh) into the $\mathrm{OB}$, which can alter olfactory learning and associated plasticity (Wilson et al., 2004; Fletcher and Chen, 2010; Ross and Fletcher, 2019). In particular, the $\mathrm{OB}$ is densely innervated by cholinergic projection neurons from the basal forebrain (Macrides et al., 1981; Záborszky et al., 1986). The cholinergic projection neurons terminate densely in the glomerular layer (Shipley and Ennis, 1996) where odor information is first processed in the brain and represented in a spatiotemporal pattern of glomerular activation unique to each odor (Wachowiak and Cohen, 2001; Spors and Grinvald, 2002; Bozza et al., 2004; Mori et al., 2006; Fletcher et al., 2009; Storace and Cohen, 2017). Both nicotinic and muscarinic ACh receptor (mAChR) subtypes are also widely expressed in the glomerular layer (Le Jeune et al., 1995; Castillo et al., 1999; Ghatpande and Gelperin, 2009; D'Souza and Vijayaraghavan, 2012) and have varied 
consequences on OB processing (Ravel et al., 1990; Elaagouby et al., 1991; Castillo et al., 1999; Liu et al., 2015; Smith et al., 2015; Case et al., 2017), providing distinct mechanisms by which ACh can modulate olfactory information.

ACh is crucial to olfactory function (Fletcher and Wilson, 2003; Bendahmane et al., 2016; Linster and Cleland, 2016; Chan et al., 2017; Ogg et al., 2018), and disruption of ACh signaling is known to affect olfactory appetitive learning across species (Ravel et al., 1994; Mandairon et al., 2006; Chaudhury et al., 2009; Devore et al., 2012; Hellier et al., 2012; Williamson and Wright, 2013; Chan et al., 2017); however, little is known regarding the extent to which cholinergic signaling affects aversive olfactory learning. Recent reports demonstrate that olfactory fear conditioning induces OB plasticity (Fletcher, 2012; Kass et al., 2013; Kass and McGann, 2017; Ross and Fletcher, 2018b), yet we lack a mechanistic understanding of the causes of such alterations. Modeling data demonstrates ACh release during olfactory learning increases mitral cell (MC) synchrony and facilitates synaptic plasticity in piriform cortex (PCx), leading to enhanced learning (de Almeida et al., 2013). In line with this, systemically inhibiting cholinergic signaling during acquisition disrupts olfactory fear learning (Kroon and Carobrez, 2009; Silva et al., 2015) but does not impair olfactory perception (Doty et al., 2003; Pavesi et al., 2012) nor alter sensitivity to unconditioned stimuli (Anagnostaras et al., 1999). Together, this demonstrates ACh is required for olfactory fear learning, possibly by enabling plasticity required for learning associations between the conditioned stimulus (CS) and unconditioned stimuli during acquisition of fear learning. Considering $\mathrm{ACh}$ is required for olfactory fear learning and its widespread innervation of the olfactory system, its role in olfactory fear learning and plasticity presents an interesting target for further investigation.

Although it has been determined that olfactory fear learning is mediated by muscarinic, not nicotinic, AChRs (Pavesi et al., 2012), the systemic nature of $\mathrm{mAChR}$ antagonism makes it difficult to conclude whether the decreased fear learning was due antagonism of $\mathrm{mAChRs}$ in olfactory regions or other affected brain regions, such amygdala or PCx which also express mAChRs (Spencer et al., 1986; Buckley et al., 1988). Modeling suggests $\mathrm{mAChRs}$ regulate synaptic plasticity in $\mathrm{PCx}$ but also increase MC synchrony in the OB, which could lead to enhanced PCx learning (Hasselmo and Barkai, 1995; de Almeida et al., 2013), making it important to establish whether $\mathrm{mAChRs}$ are required specifically in the $\mathrm{OB}$ during olfactory fear conditioning for learning to occur. Furthermore, there are two subtypes of mAChRs expressed widely in the OB and use of broad $\mathrm{mAChR}$ antagonists makes it unclear which subtypes are necessary for olfactory fear learning. While cholinergic signaling through $\mathrm{mAChRs}$ appears necessary for fear learning, the role it plays within the $\mathrm{OB}$ during associative learning has yet to be determined.

Here, we use a combination of behavioral pharmacology and optogenetics to characterize the role of $\mathrm{OB} A C h$ in olfactory fear learning. To determine the extent to which $\mathrm{OB}$ muscarinic cholinergic signaling supports fear conditioning we directly infused scopolamine (SCOP), a mAChR antagonist, into the $\mathrm{OB}$ during fear conditioning. When tested $24 \mathrm{~h}$ later, mice in which mAChRs were inhibited during odor-shock pairing, exhibit significantly reduced learned fear to the CS. By infusing specific antagonists of different $\mathrm{mAChRs}$ directly into the $\mathrm{OB}$ during olfactory fear conditioning, we identify that activation of the $\mathrm{m} 1$ subtype, but not the $\mathrm{m} 2$ subtype, of mAChRs in the $\mathrm{OB}$ is necessary for acquisition of olfactory fear learning. Furthermore, we use mice expressing channelrhodopsin in cholinergic neurons to stimulate the release of ACh specifically in the $\mathrm{OB}$ during olfactory fear conditioning and demonstrate that enhanced $\mathrm{OB} A C h$ can strengthen olfactory fear learning. This establishes that $\mathrm{OB}$ ACh can bidirectionally modulate the strength learning. Finally, we subject mice to an odor investigation task under the influence of OB SCOP and find that inhibition of mAChRs does not alter olfactory perception, and therefore cannot be the cause of suppressed learning. Altogether these results define a role for $\mathrm{ACh}$ in olfactory associative learning and $\mathrm{OB}$ glomerular plasticity.

\section{MATERIALS AND METHODS}

\section{General Methodology}

\section{Animals}

A total of 93 mice were used. OB cannula experiments were performed using adult male and female C57BL6/J (Jax Stock no: 000664) mice $(n=78)$. Optogenetic experiments were performed on adult male and female B6.Cg- $\mathrm{Tg}$ (ChatCOP4*H134R/EYFP, Slc18a3)6Gfng/J (ChAT-ChR2+) and wild-type (ChAT-ChR2-) littermates (Jax Stock No: 014546) mice $(n=15)$. All experimental protocols were approved by the University of Tennessee Institutional Animal Care and Use Committee.

\section{Surgical Procedures}

For all surgical procedures, mice were anesthetized under ketamine/xylazine $(100 / 10 \mathrm{mg} / \mathrm{kg}$, i.p.) and given carprofen (5 mg/kg, s.c.) after depth of anesthesia was verified by tail pinch. Mice were secured in a stereotaxic device and maintained on a heating pad for the duration of the surgery. All mice were implanted with a stainless steel anchor screw in the parietal bone to help secure cannula/LED to the skull. Mice used for cannula experiments (Experiments 1 and 3) received stainless steel bilateral cannula (Plastics One; C235GS5-2.0/SPC) implanted in the OBs (Bregma: $4.2 \mathrm{~mm}$ anterior, $1 \mathrm{~mm}$ lateral on either side, $1 \mathrm{~mm}$ ventral). At the end of the surgery, a dummy and cap (Plastics One; C235DCS-5/SPC and $303 \mathrm{DC} / 1 \mathrm{~B})$ were inserted into the cannula of cannulated mice. Mice used for optogenetic experiments were implanted with miniature blue LEDs (Osram; LBW5SN), following thinning of the bone overlying the OBs with a dental drill (Ogg et al., 2018). Mice were given at least 1 week to recover prior to experimentation.

\section{Drugs}

For cannulated mice, $0.5 \mu \mathrm{l}$ drug or vehicle $(\mathrm{VEH})$ infusions were delivered bilaterally at a rate of $0.125 \mu \mathrm{l} / \mathrm{min}$. Infusion 
cannula were left in place for $2 \mathrm{~min}$ following delivery to allow for diffusion. Mice received one of the following infusions either before training or before testing: non-selective muscarinic receptor antagonist SCOP hydrobromide (SCOP; Sigma-Aldrich, cat. no: S0929), selective muscarinic $\mathrm{ml}$ receptor antagonist pirenzepine dihydrochloride (PIR; Tocris Bioscience, cat. no: 1071), selective muscarinic $\mathrm{m} 2$ receptor antagonist AF-DX 116 (AFDX; Tocris Bioscience, cat. no: 1105), or an appropriate VEH [Ringer's solution or dimethyl sulfoxide (DMSO; Sigma-Aldrich, cat. no: D8418)].

\section{Olfactory Fear Conditioning and Testing}

Olfactory fear conditioning was carried out as previously described (Ross and Fletcher, 2018a). Briefly, animals were trained in a single-day classical fear conditioning paradigm where six $10 \mathrm{~s}$ presentations of a single odor, ethylvalerate (E5; Sigma-Aldrich, cat. No: 290866) diluted to $\sim 200 \mathrm{ppm}$ in mineral oil co-terminated with a $0.6 \mathrm{~mA}, 0.5 \mathrm{~s}$ foot shock. Mice were allowed to acclimate to the training chamber for $10 \mathrm{~min}$ before training began. Twenty-four hours following training, mice were placed in a separate testing context and given $10 \mathrm{~min}$ to acclimate before they were assessed for behavioral fear to the CS. Fear was measured by behavioral freezing, a widely used measure of fear (Blanchard and Blanchard, 1969a,b; Fanselow, 1980), which is characterized by cessation of voluntary movement. Testing consisted of two $20 \mathrm{~s}$ presentation of E5 (ITI $=3 \mathrm{~min}$ ), starting in the second minute of the test session. Freezing bouts, lasting a minimum of $2 \mathrm{~s}$, were calculated using FreezeFrame4 (Coulbourn Instruments), and binned into $60 \mathrm{~s}$ segments, to be reported as \% of time spent freezing during the $60 \mathrm{~s}$ bin in which odor was present.

\section{Odor Investigation}

Mice with bilateral $\mathrm{OB}$ cannula were placed in a standard shoebox cage $(18.4 \mathrm{~cm} W \times 29.2 \mathrm{~cm} D \times 12.7 \mathrm{~cm} \mathrm{H})$ devoid of bedding placed inside an open field chamber $(40 \mathrm{~cm}$ $W \times 40 \mathrm{~cm} D \times 35 \mathrm{~cm} \mathrm{H}$; Stoelting). Air or air odorized by $1 \%$ s.v. isoamylacetate (Sigma-Aldrich, cat. no: W205508) was constantly delivered to the chamber through tubing along one of the corners. The advantage of this paradigm is that it allowed for odor delivery without experimenter inference, mouse disruption, or visual/auditory cues that could result in unintended behavioral effects. A vacuum pulled air away through small holes in the chamber to prevent odor build-up. A video camera was positioned towards the side of the behavioral chambers and investigative behavior, defined as active sniffing with a raised head, was manually scored using ANY-maze (Stoelting). Ten minutes prior to placement in the chamber, mice received infusions of either $1 \mathrm{mM}$ SCOP or VEH. Mice were given $10 \mathrm{~min}$ to (with non-odorized air) before presentation of odorized air. Investigation behavior was scored for the final $120 \mathrm{~s}$ of the acclimation period and the first $60 \mathrm{~s}$ of the odor presentation.

\section{Optogenetic Stimulation}

Prior to placement in the training chamber, head-mounted LEDs were connected to a pulse generator using flexible, light-weight wires. Optogenetic stimulation occurred only during olfactory fear conditioning. The pulse generator delivered a $3 \mathrm{~s}, 50 \mathrm{~Hz}$ train starting $7.5 \mathrm{~s}$ after odor onset, such that the stimulation spanned the final $2.5 \mathrm{~s}$ of the odor presentation and the $0.5 \mathrm{~s}$ foot shock. The stimulation parameters were based on previous laboratory experiments (Ogg et al., 2018). The genetic identity of mice (ChAT-ChR2- vs. ChAT-ChR2+) was not known until after the conclusion of the experiment.

\section{Detailed Methodology}

\section{OB Pharmacology}

Experiment 1a: cannulated mice received infusions of SCOP (in Ringer's; $1 \mu \mathrm{M}, n=9 ; 1 \mathrm{mM}, n=7$; or $10 \mathrm{mM}, n=4$ ) or vehicle (Ringer's, $n=8$ ) prior to training to assess the role of $\mathrm{OB}$ muscarinic signaling in acquisition of olfactory fear learning.

Experiment 1b: cannulated mice received infusions of SCOP (in Ringer's; $1 \mathrm{mM}, n=6$ ) or vehicle (Ringer's, $n=8$ ) prior to testing to determine the extent to which $\mathrm{OB}$ muscarinic signaling is necessary for expression of learned fear.

Experiment 1c: cannulated mice received infusions of PIR (in Ringer's; $1 \mathrm{mM}, n=7$ ), AFDX (in DMSO; $1 \mathrm{mM}, n=7$ ), or vehicle (Ringers, $n=7$ and DMSO, $n=7$, respectively) prior to training to ascertain the role of specific $\mathrm{OB}$ muscarinic receptors in the acquisition of olfactory fear conditioning.

\section{Optogenetic OB Stimulation}

Experiment 2: ChAT-ChR2+ $(n=9)$ mice and their wildtype littermates (ChAT-ChR2-; $n=5$ ) received optogenetic stimulation of $\mathrm{OB}$ cholinergic fibers during olfactory fear conditioning to evaluate the extent to which enhanced OB ACh during odor-shock pairing modulates olfactory fear learning.

\section{Odor Investigation}

Experiment 3: cannulated mice received infusions of $1 \mathrm{mM}$ SCOP (in Ringers; $n=5)$ or VEH $(n=3)$ before being placed inside a standard shoebox cage located in an open field chamber. Mice were given $600 \mathrm{~s}$ to acclimate. The last $120 \mathrm{~s}$ of acclimation were recorded and scored for investigative behaviors, defined as actively sampling by sniffing with a raised head. At the end of the acclimation phase, isoamylacetate was added to the constantly circulating air stream to achieve $1 \%$ s.v. acetophenone. Investigation behavior was scored for an additional $60 \mathrm{~s}$. Each mouse was tested only once.

\section{Quantification and Statistical Analyses}

Olfactory fear learning was quantified as behavioral freezing during the test session with FreezeFrame4 automated detection software (Coulbourn Instruments) in the $60 \mathrm{~s}$ following odor presentation onset (Pavesi et al., 2012; Ross and Fletcher, 2018a). The CS, E5, was presented to each mouse two times during testing, and the freezing values for each epoch were averaged together to obtain a mean freezing score.

All statistical analyses were performed using Prism software (GraphPad, version 5.03) or SPSS (IBM, version 22). All data 
were subjected to testing for equal variances and normality. A one-tailed independent samples $t$-test was used to compare behavioral freezing between the two cannulated vehicle groups (Ringer's vs. DMSO), which revealed no significant behavioral difference $\left(t_{(12)}=0.4709, p=0.6462, M=57.960 \pm 5.527\right.$ and $54.78 \pm 3.868$, respectively) between the two vehicle controls. Therefore, Ringer's and DMSO vehicle controls were combined for analysis in Experiment 1b. ANOVAs were used for behavioral data in Experiments 1a, 1c while a one-tailed $t$-test was used for Experiments 1b, 2, and 3. Dunnett's post hoc testing was performed where appropriate. All data are presented as mean \pm SEM.

\section{RESULTS}

\section{Muscarinic Neurotransmission Is Required in the OB During Acquisition for Olfactory Fear Learning}

Previous experiments demonstrate that muscarinic, but not nicotinic, neurotransmission is required during acquisition of fear learning (Pavesi et al., 2012); however, the use of systemic drug administration could not determine whether it is specifically required in the OB. Therefore, in Experiment 1a, cannulated mice received $\mathrm{OB}$ infusions of either $\mathrm{VEH}$ or various concentrations of SCOP $(1 \mu \mathrm{M}, 1 \mathrm{mM}$, or $10 \mathrm{mM})$ in order to test whether blocking muscarinic signaling specifically in the $\mathrm{OB}$ during acquisition affects fear learning. All mice were assessed for behavioral freezing to the CS $24 \mathrm{~h}$ after training in order to measure fear learning (Figure 1A). $\mathrm{VEH}$ infused mice displayed robust behavioral freezing to the CS (mean freezing $=54.92 \% \pm 5.608$ ). Infusions of

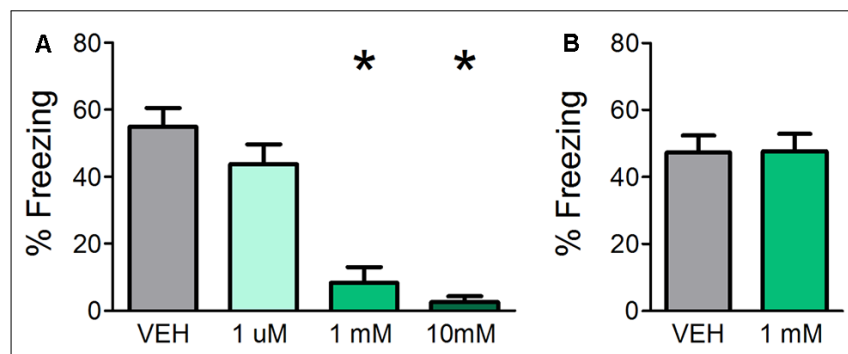

FIGURE 1 | Direct olfactory bulb (OB) application of scopolamine (SCOP) during fear conditioning impairs olfactory aversive fear learning but has no effect on the expression of previously learned fear. (A) Mice received infusions of vehicle (VEH) or different concentrations of SCOP $(1 \mu \mathrm{M}, 1 \mathrm{mM}$, or $10 \mathrm{mM})$, a non-selective antagonist of muscarinic acetylcholine receptors (mAChRs), through cannula directly into the OBs prior to olfactory fear conditioning, in which a single odor (E5) was paired with mild foot shock. Mice were tested for behavioral freezing to the conditioned odor (E5) $24 \mathrm{~h}$ later. Mice receiving infusions of $1 \mathrm{mM}$ and $10 \mathrm{mM}$ SCOP demonstrated reduced freezing relative to VEH controls, indicating impaired fear learning when mAChRs are blocked specifically in the OBs. (B) Mice were first fear-conditioned to E5. During testing, $24 \mathrm{~h}$ after conditioning, mice received direct $\mathrm{OB}$ infusions of $\mathrm{VEH}$ or $1 \mathrm{mM}$ SCOP. There is no significant difference in behavioral freezing between mice receiving infusions of $\mathrm{VEH}$ or $1 \mathrm{mM}$ SCOP, signifying antagonism of $\mathrm{mAChRs}$ during expression does not affect olfactory perception or behavioral displays of learned olfactory fear. Data presented as mean \pm SEM. ${ }^{*} p<0.05$.
SCOP prior to training significantly impeded fear learning $\left(F_{(3,24)}=19.724, p<0.0001, \eta^{2}=0.711\right)$. While the lowest SCOP dose $(1 \mu \mathrm{M})$ did not impact fear learning relative to $\mathrm{VEH}$ mice (mean freezing $=43.80 \% \pm 5.9, p=0.309$ ), higher doses of $1 \mathrm{mM}$ and $10 \mathrm{mM}$ significantly decreased freezing (mean freezing $=8.31 \% \pm 4.7, p \leq 0.0001$ and mean freezing $=2.55 \% \pm 1.7, p<0.0001$, respectively). These results confirm that muscarinic neurotransmission is required for fear learning and establish that it is necessary specifically in the $\mathrm{OB}$ during acquisition.

\section{OB Muscarinic Neurotransmission Is Not Required for Expression of Olfactory Fear Learning}

Experiment 1a indicates that $\mathrm{OB}$ cholinergic signaling during acquisition is necessary for olfactory fear learning; however, the extent to which muscarinic neurotransmission is required during expression of fear learning is unclear. Therefore, in Experiment $1 b$, we first subjected mice to olfactory fear conditioning and then infused either SCOP ( $1 \mathrm{mM}$, based on the efficacy of $1 \mathrm{mM}$ SCOP in preventing fear learning when administered prior to training in Experiment 1a) of $\mathrm{VEH}$ prior to behavioral testing $24 \mathrm{~h}$ after training (Figure 1B). Blocking muscarinic receptors via OB SCOP infusion (mean freezing $=47.27 \% \pm 5.1$ ) during testing had no effect on behavioral freezing relative to $\mathrm{VEH}$ controls (mean freezing $=47.66 \% \pm 5.2 ; t_{(12)}=0.05283, p=0.4794$ ), indicating $\mathrm{OB}$ muscarinic signaling is not required during the expression of a previously learned olfactory fear.

\section{OB Muscarinic Neurotransmission, Specifically Through mAChR1, Is Required for Fear Learning}

SCOP is a non-selective antagonist of mAChRs. There are two types of mAChRs expressed widely in the OB, mAChR1 and $\mathrm{mAChR} 2$. In order to determine which of the receptor subtypes are necessary for fear learning, we infused specific antagonists for either mAChR1 (PIR) or mAChR2 (AFDX) or appropriate $\mathrm{VEH}$ in different mice prior to training. Mice receiving Ringer's $\mathrm{VEH}$ and DMSO VEH were combined into a single VEH comparison group after statistical testing revealed no significant difference between the two VEH controls (Figure 2A). Both antagonists for Experiment 1c were delivered at a concentration of $1 \mathrm{mM}$ based on the efficacy of $1 \mathrm{mM}$ SCOP in Experiment 1a. Mice were tested for behavioral freezing, as a measure of learned fear, $24 \mathrm{~h}$ after fear conditioning (Figure 2B). Mice receiving $\mathrm{VEH}$ infusions prior to training exhibited robust freezing to the CS (mean freezing $=56.37 \% \pm 3.3$ ). As expected, inhibiting $\mathrm{mAChRs}$ blocked fear learning $\left(F_{(2,25)}=12.111, p=0.0002, \eta^{2}=0.4921\right)$; however, only infusions of PIR (mean freezing $=33.87 \% \pm 4.5$ ), not AFDX (mean freezing $=63.44 \% \pm 4.3$ ), decreased CS-evoked freezing relative to $\mathrm{VEH}$ mice ( $p=0.001$ and $p=0.367$, respectively). This suggests cholinergic signaling through $\mathrm{mAChR} 1$, but not mAChR2, during training is required for olfactory fear learning. 

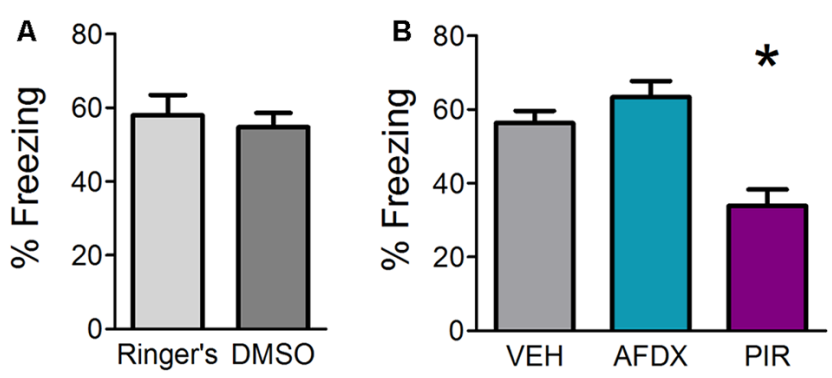

FIGURE 2 | Inhibition of mAChR1, but not mAChR2, decreases behavioral freezing to the conditioned odor. Mice received direct $\mathrm{OB}$ infusions of vehicle [VEH, either Ringer's or dimethyl sulfoxide (DMSO)] or AFDX, a specific antagonist of the $\mathrm{m} 2$ subtype of mAChRs, or PIR, a specific antagonist of the m1 subtype of mAChRs, prior to olfactory fear conditioning. The mice were then tested for behavioral freezing $24 \mathrm{~h}$ later. (A) Mice receiving Ringer's VEH and those receiving DMSO VEH prior to conditioning do not exhibit different freezing during testing, indicating no difference in learning as a result of the different VEH conditions. (B) There is no significant difference in freezing between VEH mice (combined Ringer's and DMSO) and those receiving infusions of the mAChR2 antagonist AFDX; however, mice treated with PIR before conditioning display reduced freezing relative to VEH mice, suggesting mAChR1 s specifically are required for appropriate acquisition of olfactory fear. Data presented as mean \pm SEM. ${ }^{*} p<0.05$.

\section{Stimulating Release of OB ACh During Odor-Shock Pairing Strengthens Olfactory Fear Learning}

Optogenetic OB stimulation has previously been shown to cause behavioral dishabituation of ChAT-ChR2+ but not wild-type (ChAT-ChR2-) littermates (Ogg et al., 2018), consistent with the idea that the stimulation paradigm induces release of ACh into the $\mathrm{OB}$. Given that ACh is necessary during conditioning in order to acquire olfactory fear, we next tested whether supplemental $\mathrm{OB}$ ACh could augment fear learning. In Experiment 2, we optogenetically stimulated release of $\mathrm{OB}$ ACh specifically during each of the six odor-shock pairings and tested behavioral freezing $24 \mathrm{~h}$ later (Figure 3). ChAT-ChR2+ mice displayed augmented freezing (mean freezing $=61.04 \% \pm 5.0$ ) during testing relative to ChAT-ChR2 - mice (mean freezing $=43.9 \% \pm 6.3 ; t_{(12)}=2.077$, $p=0.030$ ). These results suggest that increasing $\mathrm{OB}$ ACh during acquisition of olfactory fear learning can enhance the strength of the learned association.

\section{Olfactory Investigative Behavior Is Not Affected by Direct OB Antagonism of mAChRs}

While previous reports indicate mice lacking certain mAChRs exhibit normal basic olfactory investigation (Chan et al., 2017) and systemic administration of the mAChR antagonist SCOP does not impair olfactory perception (Doty et al., 2003; Pavesi et al., 2012), it is unclear whether direct $\mathrm{OB}$ application of mAChR antagonists affects olfactory behaviors. In order to determine whether the observed learning impairments were a result of reduced olfactory perception following mAChR antagonism, we subjected mice to an olfactory investigation task in Experiment 3 to assess olfactory function.

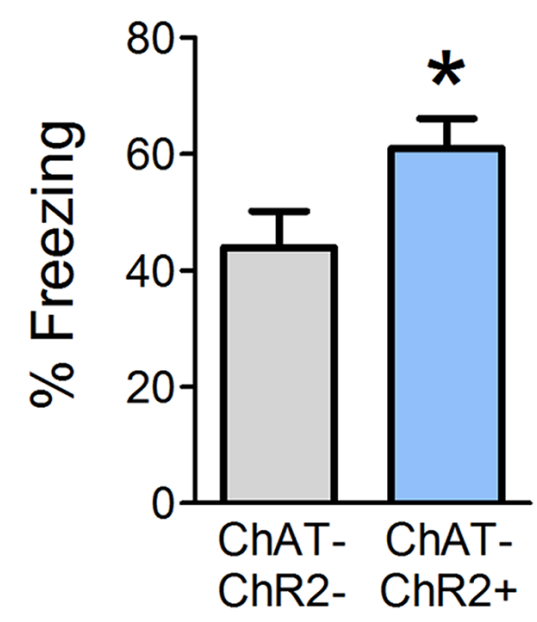

FIGURE 3 | Enhanced OB ACh during odor-shock pairing augments olfactory fear learning. Mice were surgically implanted with a miniature LED directly above the OBs. During olfactory fear conditioning, all mice received light stimulation at the end of each of the six odor-shock pairings. Positive ChAT-ChR2 mice express channelrhodopsin in cholinergic cell populations, such that light stimulation should induce release of ACh in the OBs during odor-shock pairing. When tested $24 \mathrm{~h}$ later, ChAT-ChR2+ mice freeze significantly more than ChAT-ChR2 - mice, which do not express channelrhodopsin in cholinergic cell populations and should experience no additional ACh release in the OBs as a result of light stimulation. This suggests that increasing OB ACh during olfactory fear conditioning can strengthen fear learning. Data presented as mean \pm SEM. ${ }^{*} p<0.05$.

In Experiment 3 (Figure 4), OB administration of SCOP ( $1 \mathrm{mM}$ ) did not affect investigation of an odorized ball relative to $\mathrm{VEH}\left(t_{(6)}=1.483, p=0.0943\right)$. Mice spent the same amount of time performing investigatory behaviors during odor presentation regardless of whether they had received an $\mathrm{OB}$ infusion of $\mathrm{VEH}$ or SCOP (Investigation time $=29.9 \pm 2.2 \mathrm{~s}$ and $33.4 \pm 1.3 \mathrm{~s}$, respectively). Together these experiments indicate that SCOP, administered either systemically or directly in the OBs, does not induce anosmia nor altered olfactory perception.

\section{DISCUSSION}

Using a combination of in vivo pharmacology and optogenetics in conjunction with olfactory fear conditioning, we investigated the role of ACh neurotransmission in olfactory fear learning. Previous work demonstrates that systemic administration of nicotinic AChR antagonists during conditioning does not alter fear learning, while systemic administration of mAChRs during acquisition suppresses olfactory fear learning (Pavesi et al., 2012). Therefore, we aimed to determine whether $\mathrm{mAChRs}$ specifically in the $\mathrm{OB}$ are required for acquisition of olfactory fear. The results demonstrate that acquisition, but not expression, of olfactory fear learning requires ACh neurotransmission through muscarinic receptors, specifically $\mathrm{mAChR} 1$, in the OB. Importantly, direct $\mathrm{OB}$ antagonism of $\mathrm{mAChRs}$ does not alter olfactory-driven behaviors, establishing that the lack of learning is not a consequence of reversible anosmia during olfactory fear conditioning. Finally, stimulating 


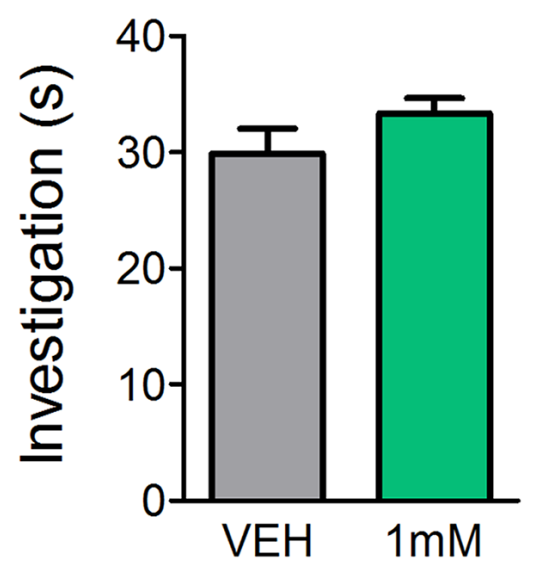

FIGURE 4 | Antagonism of mAChRs does not alter olfactory-driven behaviors. Mice underwent an olfactory investigation paradigm inside an open field chamber to determine whether the mAChR antagonist, SCOP, alters olfactory behaviors. Cannulated mice received direct $O B$ infusions of either $1 \mathrm{mM}$ SCOP or VEH. Time spent performing olfactory investigative behaviors was then scored in response to uncued odor presentations. Mice receiving OB SCOP did not differ from those receiving $\mathrm{VEH}$ in terms of time spent investigating. Together, this demonstrates non-specific antagonism of mAChRs does not alter olfactory-driven behaviors or induce temporary anosmia. Data presented as mean \pm SEM.

release of $\mathrm{OB}$ ACh during odor-shock pairing appears to increase the strength of fear learning. Together, these studies provide a new role for $\mathrm{ACh}$ in associative olfactory fear learning; however, the exact mechanism by which mAChR activation during odor-shock pairing allows for acquisition of fear learning remains unknown.

Our findings confirm previous reports that mAChRs are inextricably linked to olfactory learning. Both genetic (Chan et al., 2017) and pharmacological inhibition of mAChRs suppresses olfactory appetitive and aversive learning (Ravel et al., 1994; Kroon and Carobrez, 2009; Pavesi et al., 2012; Devore et al., 2014; Silva et al., 2015). This, combined with the present results, suggests that mAChRs play a similar role in acquisition of appetitive and aversive learning. We expand on these previous reports by demonstrating direct $\mathrm{OB}$ ACh signaling, specifically through $\mathrm{mAChR}$, is required during olfactory fear conditioning; however, the underlying mechanism remains unclear. One possibility is that the concentration of the mAChR1 antagonist (PIR) used $(1 \mathrm{mM})$ is too high to exert a specific effect on $\mathrm{ml}$ receptors and may be acting as an inverse agonist of $\mathrm{m} 2$ receptors (Daeffler et al., 1999); however, we find no effect of antagonizing mAChR2 receptors on learning at the same concentration. This suggests that even if PIR is modulating both $\mathrm{mAChR} 1$ and $\mathrm{mAChR} 2$ receptors at this concentration, the observed effect is specific to antagonism of $\mathrm{mAChR} 1$ receptors. ACh is known to modulate several OB cell types including MCs, granule cells (GCs), and periglomerular cells (Nickell and Shipley, 1988; Ravel et al., 1990; Castillo et al., 1999; Pressler et al., 2007; Chaudhury et al., 2009), but studies suggest that activation of mAChRs, especially mAChR1, increases excitability of GCs (Pressler et al., 2007; Smith and Araneda, 2010; Smith et al., 2015). Given olfactory learning is impeded when antagonism of mAChRs is confined to the GC layer but not affected when antagonism is confined to the glomerular layer (Ravel et al., 1994), mAChRs most likely modulate the MC/GC circuit, which increases synchronization of MC spike timing and oscillatory power (Li and Cleland, 2013). Models including pharmacological blockade of mAChRs in the $\mathrm{OB}$ result in altered $\mathrm{OB}$ network dynamics, which, in turn, decreases the activation of $\mathrm{PCx}$, cortical plasticity, and learning (Devore et al., 2014). This may suggest the role of mAChRs during learning is to regulate olfactory input to $\mathrm{PCx}$ to enable olfactory learning. If this is the main function of mAChRs, muscarinic signaling in the $\mathrm{OB}$ is also likely required for appetitive learning, which future studies should investigate. While the exact downstream mechanisms are yet to be determined, activation of $\mathrm{OB}$ mAChRs in olfactory aversive learning likely regulates $\mathrm{OB}$ output, which ultimately leads to olfactory learning. Interestingly, our findings replicate previous reports that $\mathrm{ACh}$ modulation primarily affects acquisition but has little to no effect on expression of previous olfactory learning (Saar et al., 2001; Chapuis and Wilson, 2013; Linster and Cleland, 2016).

We also demonstrate that stimulating release of $\mathrm{OB} \mathrm{ACh}$ during odor-shock pairing appears to increase the strength of fear learning. Optogenetic stimulation of OB ACh release cannot determine whether the facilitated learning is an effect of signaling through nicotinic AChRs, mAChRs, or both, and future studies are needed to determine the extent to which these different AChRs and their subtypes contribute to enhancement of olfactory fear learning. However, several previous reports establish that $\mathrm{ACh}$ release into the $\mathrm{OB}$ and subsequent activation of AChRs can modulate excitability of OB glomeruli and OB output cells (Chaudhury et al., 2009; Devore et al., 2012; Ma and Luo, 2012; Rothermel et al., 2014; Bendahmane et al., 2016). Enhanced synchrony and strengthened $\mathrm{OB}$ output could explain how optogenetically increasing $\mathrm{OB}$ ACh during odor-shock pairing results in strengthened olfactory learning. This idea is in line with previous reports that high ACh facilitates learning by enabling long term potentiation (Linster and Cleland, 2016). Another possibility is that $\mathrm{OB} \mathrm{ACh}$ reduces the inhibitory drive of OB GCs, which could facilitate transmission of olfactory information from $\mathrm{OB}$ output neurons to higher processing centers (Elaagouby et al., 1991; Kay and Beshel, 2010; Kay, 2014; Osinski et al., 2018). Altering inhibitory drive of GCs could also lead to decreased inhibition of neighboring GCs (Castillo et al., 1999) thereby sharpening the receptive fields of $\mathrm{OB}$ output cells. It is also likely that activation of AChRs could inhibit glomerular layer inhibitory interneurons neurons (Crespo et al., 2000; Pignatelli and Belluzzi, 2008; Liu et al., 2015), leading to increased responses of excitatory cells. It is also possible that optogenetically stimulating cholinergic axons in the $\mathrm{OB}$ might produce back-propagation of action potentials to cholinergic soma, which could cause ACh release in multiple brain regions. Therefore, it is possible the facilitated learning following stimulated $\mathrm{OB}$ ACh release is actually due to non-specific ACh release. However, a recent study traced projections of basal forebrain cholinergic cells and found 
minimal cholinergic cells projecting to the main $\mathrm{OB}$ that also project to another region of the brain (Li et al., 2018), suggesting non-specific release is an unlikely explanation for the facilitated learning. Future electrophysiological experiments are needed to understand the exact role of $\mathrm{ACh}$ in facilitating olfactory aversive learning.

In summary, this study reveals new insights into the role of ACh in olfactory associative aversive learning. Previous reports using systemic antagonists indicated mAChRs, but not nicotinic AChRs, are required during odor-shock pairing for olfactory learning to take place. However, this did not address whether ACh signaling through $\mathrm{mAChRs}$ is required in the $\mathrm{OB}$ nor the extent to which olfactory aversive learning is mediated by specific mAChR subtypes. Using OB infusion of $\mathrm{mAChR}$ antagonists, we were able to determine that activation of $\mathrm{mAChRs}$, specifically the $\mathrm{m} 1$ subtype, is required directly in the OB during odor-shock pairing for acquisition of olfactory fear learning. Additionally, we were able to confirm previous reports that blockade of $\mathrm{mAChRs}$ does not interfere with expression of previously learned olfactory fear. Furthermore, optogenetic stimulation of $\mathrm{OB}$ ACh during odor-shock pairing appears to increase the strength of olfactory learning. Together these studies demonstrate the importance of $\mathrm{OB}$ ACh for olfactory learning and related plasticity.

\section{REFERENCES}

Anagnostaras, S. G., Maren, S., Sage, J. R., Goodrich, S., and Fanselow, M. S. (1999). Scopolamine and Pavlovian fear conditioning in rats: dose-effect analysis. Neuropsychopharmacology 21, 731-744. doi: 10.1016/s0893-133x(99)00083-4

Bendahmane, M., Ogg, M. C., Ennis, M., and Fletcher, M. L. (2016). Increased olfactory bulb acetylcholine bi-directionally modulates glomerular odor sensitivity. Sci. Rep. 6:25808. doi: 10.1038/srep25808

Blanchard, R. J., and Blanchard, D. C. (1969a). Crouching as an index of fear. J. Comp. Physiol. Psychol. 67, 370-375. doi: 10.1037/h0026779

Blanchard, R. J., and Blanchard, D. C. (1969b). Passive and active reactions to fear-eliciting stimuli. J. Comp. Physiol. Psychol. 68, 129-135. doi: $10.1037 / \mathrm{h} 0027676$

Bozza, T., McGann, J. P., Mombaerts, P., and Wachowiak, M. (2004). In vivo imaging of neuronal activity by targeted expression of a genetically encoded probe in the mouse. Neuron 42, 9-21. doi: 10.1016/s0896-6273(04) 00144-8

Buckley, N. J., Bonner, T. I., and Brann, M. R. (1988). Localization of a family of muscarinic receptor mRNAs in rat brain. J. Neurosci. 8, 4646-4652. doi: 10.1523/JNEUROSCI.08-12-04646.1988

Case, D. T., Burton, S. D., Gedeon, J. Y., Williams, S. G., Urban, N. N., and Seal, R. P. (2017). Layer- and cell type-selective co-transmission by a basal forebrain cholinergic projection to the olfactory bulb. Nat. Commun. 8:652. doi: 10.1038/s41467-017-00765-4

Castillo, P. E., Carleton, A., Vincent, J. D., and Lledo, P. M. (1999). Multiple and opposing roles of cholinergic transmission in the main olfactory bulb. J. Neurosci. 19, 9180-9191. doi: 10.1523/JNEUROSCI.19-21-09180.1999

Chan, W., Singh, S., Keshav, T., Dewan, R., Eberly, C., Maurer, R., et al. (2017). Mice lacking M1 and M3 muscarinic acetylcholine receptors have impaired odor discrimination and learning. Front. Synaptic. Neurosci. 9:4. doi: 10.3389/fnsyn.2017.00004

Chapuis, J., and Wilson, D. A. (2013). Cholinergic modulation of olfactory pattern separation. Neurosci. Lett. 545, 50-53. doi: 10.1016/j.neulet.2013. 04.015

Chaudhury, D., Escanilla, O., and Linster, C. (2009). Bulbar acetylcholine enhances neural and perceptual odor discrimination. J. Neurosci. 29, 52-60. doi: 10.1523/JNEUROSCI.4036-08.2009

\section{DATA AVAILABILITY}

The raw data supporting the conclusions of this manuscript will be made available by the authors, without undue reservation, to any qualified researcher.

\section{ETHICS STATEMENT}

All experimental protocols were approved by the University of Tennessee Institutional Animal Care and Use Committee.

\section{AUTHOR CONTRIBUTIONS}

$\mathrm{JR}, \mathrm{MB}$, and MF designed the experiments. JR and MB performed all experiments, analyzed and interpreted the collected data. JR wrote the manuscript.

\section{FUNDING}

The research reported in this publication was supported by the National Institute on Deafness and Other Communication Disorders (NIDCD) awards R01DC013779 to MF and F31DC016485 to JR.

Crespo, C., Blasco-Ibáñez, J. M., Briñón, J. G., Alonso, J. R., Domínguez, M. I., and Martínez-Guijarro, F. J. (2000). Subcellular localization of m2 muscarinic receptors in GABAergic interneurons of the olfactory bulb. Eur. J. Neurosci. 12, 3963-3974. doi: 10.1046/j.1460-9568.2000.00289.x

Daeffler, L., Schmidlin, F., Gies, J. P., and Landry, Y. (1999). Inverse agonist activity of pirenzepine at M2 muscarinic acetylcholine receptors. Br. J. Pharmacol. 126, 1246-1252. doi: 10.1038/sj.bjp.0702407

de Almeida, L., Idiart, M., and Linster, C. (2013). A model of cholinergic modulation in olfactory bulb and piriform cortex. J. Neurophysiol. 109, 1360-1377. doi: 10.1152/jn.00577.2012

Devore, S., de Almeida, L., and Linster, C. (2014). Distinct roles of bulbar muscarinic and nicotinic receptors in olfactory discrimination learning. J. Neurosci. 34, 11244-11260. doi: 10.1523/JNEUROSCI.1499 $-14.2014$

Devore, S., Manella, L. C., and Linster, C. (2012). Blocking muscarinic receptors in the olfactory bulb impairs performance on an olfactory short-term memory task. Front. Behav. Neurosci. 6:59. doi: 10.3389/fnbeh.2012. 00059

Doty, R. L., Bagla, R., Misra, R., Mueller, E., and Kerr, K. L. (2003). No influence of scopolamine hydrobromide on odor detection performance of rats. Chem. Senses 28, 761-765. doi: 10.1093/chemse/bjg067

D'Souza, R. D., and Vijayaraghavan, S. (2012). Nicotinic receptor-mediated filtering of mitral cell responses to olfactory nerve inputs involves the

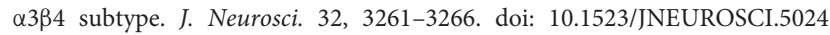
$-11.2012$

Elaagouby, A., Ravel, N., and Gervais, R. (1991). Cholinergic modulation of excitability in the rat olfactory bulb: effect of local application of cholinergic agents on evoked field potentials. Neuroscience 45, 653-662. doi: 10.1016/03064522(91)90278-v

Fanselow, M. S. (1980). Conditioned and unconditional components of post-shock freezing. Pavlov. J. Biol. Sci. 15, 177-182.

Fletcher, M. L. (2012). Olfactory aversive conditioning alters olfactory bulb mitral/tufted cell glomerular odor responses. Front. Syst. Neurosci. 6:16. doi: 10.3389/fnsys.2012.00016

Fletcher, M. L., and Chen, W. R. (2010). Neural correlates of olfactory learning: critical role of centrifugal neuromodulation. Learn. Mem. 17, 561-570. doi: $10.1101 / \mathrm{lm} .941510$ 
Fletcher, M. L., Masurkar, A. V., Xing, J., Imamura, F., Xiong, W., Nagayama, S., et al. (2009). Optical imaging of postsynaptic odor representation in the glomerular layer of the mouse olfactory bulb. J. Neurophysiol. 102, 817-830. doi: $10.1152 /$ jn.00020.2009

Fletcher, M. L., and Wilson, D. A. (2003). Olfactory bulb mitral-tufted cell plasticity: odorant-specific tuning reflects previous odorant exposure. J. Neurosci. 23, 6946-6955. doi: 10.1523/JNEUROSCI.23-17-06946.2003

Ghatpande, A. S., and Gelperin, A. (2009). Presynaptic muscarinic receptors enhance glutamate release at the mitral/tufted to granule cell dendrodendritic synapse in the rat main olfactory bulb. J. Neurophysiol. 101, 2052-2061. doi: $10.1152 /$ jn. 90734.2008

Hasselmo, M. E., and Barkai, E. (1995). Cholinergic modulation of activitydependent synaptic plasticity in the piriform cortex and associative memory function in a network biophysical simulation. J. Neurosci. 15, 6592-6604. doi: 10.1523/JNEUROSCI.15-10-06592.1995

Hellier, J. L., Arevalo, N. L., Smith, L., Xiong, K. N., and Restrepo, D. (2012). $\alpha 7$-Nicotinic acetylcholine receptor: role in early odor learning preference in mice. PLoS One 7:e35251. doi: 10.1371/journal.pone.0035251

Kass, M. D., and McGann, J. P. (2017). Persistent, generalized hypersensitivity of olfactory bulb interneurons after olfactory fear generalization. Neurobiol. Learn. Mem. 146, 47-57. doi: 10.1016/j.nlm.2017.11.004

Kass, M. D., Rosenthal, M. C., Pottackal, J., and McGann, J. P. (2013). Fear learning enhances neural responses to threat-predictive sensory stimuli. Science 342, 1389-1392. doi: 10.1126/science. 1244916

Kay, L. M. (2014). Circuit oscillations in odor perception and memory. Prog. Brain Res. 208, 223-251. doi: 10.1016/b978-0-444-63350-7.00009-7

Kay, L. M., and Beshel, J. (2010). A $\beta$ oscillation network in the rat olfactory system during a 2-alternative choice odor discrimination task. J. Neurophysiol. 104, 829-839. doi: 10.1152/jn.00166.2010

Kroon, J. A., and Carobrez, A. P. (2009). Olfactory fear conditioning paradigm in rats: effects of midazolam, propranolol or scopolamine. Neurobiol. Learn. Mem. 91, 32-40. doi: 10.1016/j.nlm.2008.10.007

Le Jeune, H., Aubert, I., Jourdan, F., and Quirion, R. (1995). Comparative laminar distribution of various autoradiographic cholinergic markers in adult rat main olfactory bulb. J. Chem. Neuroanat. 9, 99-112. doi: 10.1016/08910618(95)00070-n

Li, G., and Cleland, T. A. (2013). A two-layer biophysical model of cholinergic neuromodulation in olfactory bulb. J. Neurosci. 33, 3037-3058. doi: 10.1523/JNEUROSCI.2831-12.2013

Li, X., Yu, B., Sun, Q., Zhang, Y., Ren, M., Zhang, X., et al. (2018). Generation of a whole-brain atlas for the cholinergic system and mesoscopic projectome analysis of basal forebrain cholinergic neurons. Proc. Natl. Acad. Sci. U S A 115, 415-420. doi: 10.1073/pnas.1703601115

Linster, C., and Cleland, T. A. (2016). Neuromodulation of olfactory transformations. Curr. Opin. Neurobiol. 40, 170-177. doi: 10.1016/j.conb. 2016.07.006

Liu, S., Shao, Z., Puche, A., Wachowiak, M., Rothermel, M., and Shipley, M. T. (2015). Muscarinic receptors modulate dendrodendritic inhibitory synapses to sculpt glomerular output. J. Neurosci. 35, 5680-5692. doi: 10.1523/jneurosci. 4953-14.2015

Ma, M., and Luo, M. (2012). Optogenetic activation of basal forebrain cholinergic neurons modulates neuronal excitability and sensory responses in the main olfactory bulb. J. Neurosci. 32, 10105-10116. doi: 10.1523/jneurosci.0058 $-12.2012$

Macrides, F., Davis, B. J., Youngs, W. M., Nadi, N. S., and Margolis, F. L. (1981). Cholinergic and catecholaminergic afferents to the olfactory bulb in the hamster: a neuroanatomical, biochemical and histochemical investigation. J. Comp. Neurol. 203, 495-514. doi: 10.1002/cne.902030311

Mandairon, N., Ferretti, C. J., Stack, C. M., Rubin, D. B., Cleland, T. A., and Linster, C. (2006). Cholinergic modulation in the olfactory bulb influences spontaneous olfactory discrimination in adult rats. Eur. J. Neurosci. 24, 3234-3244. doi: 10.1111/j.1460-9568.2006.05212.x

Mori, K., Takahashi, Y. K., Igarashi, K. M., and Yamaguchi, M. (2006). Maps of odorant molecular features in the Mammalian olfactory bulb. Physiol. Rev. 86, 409-433. doi: 10.1152/physrev.00021.2005

Nickell, W. T., and Shipley, M. T. (1988). Two anatomically specific classes of candidate cholinoceptive neurons in the rat olfactory bulb. J. Neurosci. 8, 4482-4491. doi: 10.1523/jneurosci.08-12-04482.1988
Ogg, M. C., Ross, J. M., Bendahmane, M., and Fletcher, M. L. (2018). Olfactory bulb acetylcholine release dishabituates odor responses and reinstates odor investigation. Nat. Commun. 9:1868. doi: 10.1038/s41467-018-04371-w

Osinski, B. L., Kim, A., Xiao, W., Mehta, N. M., and Kay, L. M. (2018). Pharmacological manipulation of the olfactory bulb modulates $\beta$ oscillations: testing model predictions. J. Neurophysiol. 120, 1090-1106. doi: 10.1152/jn. 00090.2018

Pavesi, E., Gooch, A., Lee, E., and Fletcher, M. L. (2012). Cholinergic modulation during acquisition of olfactory fear conditioning alters learning and stimulus generalization in mice. Learn. Mem. 20, 6-10. doi: 10.1101/lm.028324.112

Pignatelli, A., and Belluzzi, O. (2008). Cholinergic modulation of dopaminergic neurons in the mouse olfactory bulb. Chem. Senses 33, 331-338. doi: 10.1093/chemse/bjm091

Pressler, R. T., Inoue, T., and Strowbridge, B. W. (2007). Muscarinic receptor activation modulates granule cell excitability and potentiates inhibition onto mitral cells in the rat olfactory bulb. J. Neurosci. 27, 10969-10981. doi: 10.1523/jneurosci.2961-07.2007

Ravel, N., Akaoka, H., Gervais, R., and Chouvet, G. (1990). The effect of acetylcholine on rat olfactory bulb unit activity. Brain Res. Bull. 24, 151-155. doi: 10.1016/0361-9230(90)90199-a

Ravel, N., Elaagouby, A., and Gervais, R. (1994). Scopolamine injection into the olfactory bulb impairs short-term olfactory memory in rats. Behav. Neurosci. 108, 317-324. doi: 10.1037//0735-7044.108.2.317

Ross, J. M., and Fletcher, M. L. (2018a). Assessing classical olfactory fear conditioning by behavioral freezing in mice. Bio Protoc. 8:e3013. doi: 10.21769/bioprotoc. 3013

Ross, J. M., and Fletcher, M. L. (2018b). Learning-dependent and -independent enhancement of mitral/tufted cell glomerular odor responses following olfactory fear conditioning in awake mice. J. Neurosci. 38, 4623-4640. doi: 10.1523/jneurosci.3559-17.2018

Ross, J. M., and Fletcher, M. L. (2019). Aversive learning-induced plasticity throughout the adult mammalian olfactory system: insights across development. J. Bioenerg. Biomembr. 51, 15-27. doi: 10.1007/s10863-0189770-z

Rothermel, M., Carey, R. M., Puche, A., Shipley, M. T., and Wachowiak, M. (2014). Cholinergic inputs from Basal forebrain add an excitatory bias to odor coding in the olfactory bulb. J. Neurosci. 34, 4654-4664. doi: 10.1523/jneurosci.502613.2014

Saar, D., Grossman, Y., and Barkai, E. (2001). Long-lasting cholinergic modulation underlies rule learning in rats. J. Neurosci. 21, 1385-1392. doi: 10.1523/jneurosci.21-04-01385.2001

Shipley, M. T., and Ennis, M. (1996). Functional organization of olfactory system. J. Neurobiol. 30, 123-176. doi: 10.1002/(SICI)10974695(199605)30:1<123::AID-NEU11 > 3.0.CO;2-N

Silva, B., Molina-Fernández, C., Ugalde, M. B., Tognarelli, E. I., Angel, C., and Campusano, J. M. (2015). Muscarinic ACh receptors contribute to aversive olfactory learning in Drosophila. Neural Plast. 2015:658918. doi: $10.1155 / 2015 / 658918$

Smith, R. S., and Araneda, R. C. (2010). Cholinergic modulation of neuronal excitability in the accessory olfactory bulb. J. Neurophysiol. 104, 2963-2974. doi: 10.1152 /jn.00446.2010

Smith, R. S., Hu, R., DeSouza, A., Eberly, C. L., Krahe, K., Chan, W., et al. (2015). Differential muscarinic modulation in the olfactory bulb. J. Neurosci. 35, 10773-10785. doi: 10.1523/jneurosci.0099-15.2015

Spencer, D. G. Jr., Horváth, E., and Traber, J. (1986). Direct autoradiographic determination of M1 and M2 muscarinic acetylcholine receptor distribution in the rat brain: relation to cholinergic nuclei and projections. Brain Res. 380 , 59-68. doi: 10.1016/0006-8993(86)91429-0

Spors, H., and Grinvald, A. (2002). Spatio-temporal dynamics of odor representations in the mammalian olfactory bulb. Neuron 34, 301-315. doi: 10.1016/s0896-6273(02)00644-x

Storace, D. A., and Cohen, L. B. (2017). Measuring the olfactory bulb inputoutput transformation reveals a contribution to the perception of odorant concentration invariance. Nat. Commun. 8:81. doi: 10.1038/s41467-017 $-00036-2$

Wachowiak, M., and Cohen, L. B. (2001). Representation of odorants by receptor neuron input to the mouse olfactory bulb. Neuron 32, 723-735. doi: $10.1016 /$ s0896-6273(01)00506-2 
Williamson, S. M., and Wright, G. A. (2013). Exposure to multiple cholinergic pesticides impairs olfactory learning and memory in honeybees. J. Exp. Biol. 216, 1799-1807. doi: 10.1242/jeb.083931

Wilson, D. A., Fletcher, M. L., and Sullivan, R. M. (2004). Acetylcholine and olfactory perceptual learning. Learn. Mem. 11, 28-34. doi: 10.1101/lm. 66404

Záborszky, L., Carlsen, J., Brashear, H. R., and Heimer, L. (1986). Cholinergic and GABAergic afferents to the olfactory bulb in the rat with special emphasis on the projection neurons in the nucleus of the horizontal limb of the diagonal band. J. Comp. Neurol. 243, 488-509. doi: 10.1002/cne.9024 30405
Conflict of Interest Statement: The authors declare that the research was conducted in the absence of any commercial or financial relationships that could be construed as a potential conflict of interest.

Copyright (C) 2019 Ross, Bendahmane and Fletcher. This is an open-access article distributed under the terms of the Creative Commons Attribution License (CC BY). The use, distribution or reproduction in other forums is permitted, provided the original author(s) and the copyright owner(s) are credited and that the original publication in this journal is cited, in accordance with accepted academic practice. No use, distribution or reproduction is permitted which does not comply with these terms. 